\title{
AN EXPERIMENTAL INVESTIGATION INTO MOISTURE-INDUCED EXPANSION OF PLASTERS
}

\author{
Radoslav Sovják ${ }^{a, *}$, Tomáš KoreckÝ $^{b}$, Aleksander Gundersen $^{c}$ \\ ${ }^{a}$ Czech Technical University in Prague, Faculty of Civil Engineering, Experimental Centre, Thákurova 7, CZ-166 \\ 29 Prague \\ ${ }^{b}$ Czech Technical University in Prague, Faculty of Civil Engineering, Department of Materials Engineering and \\ Chemistry, Thákurova 7, CZ-166 29 Prague \\ ${ }^{c}$ Norwegian University of Science and Technology, Faculty of Engineering Science and Technology, \\ Høgskoleringen 6, NO-7491 Trondheim \\ * corresponding author: sovjak@fsv.cvut.cz
}

\begin{abstract}
This paper presents an experimental study on moisture-induced expansion of selected plasters. Contactless measurement is introduced and a coefficient of moisture expansion for different building plasters is established. It is found that stresses which might develop in building materials due to moisture variations are equal to or higher than stresses which might be caused by temperature variations.
\end{abstract}

KEYWORDS: adsorption; absorption; hygric expansion; hydric expansion; plasters; experimental measurement.

\section{INTRODUCTION}

Building materials and structures are subjected to a number of climate actions. Many buildings become disfigured soon after their completion or later after many repetitions of climate actions or as a result of synergies with other physical or chemical effects. Typical defects include the cracking of finishes and the spalling of surfaces. Many authors agree that the mechanisms responsible for such failures are usually associated with length or volume changes of porous materials due to increased moisture content or to temperature changes [1-3].

Deformation caused by moisture changes is called hygric in the range between $0 \% \mathrm{RH}$ and $95 \% \mathrm{RH}$, and hydric when the material is in contact with or immersed in water [4]. Hygric deformation is due to the predisposition of the material to adsorb water. Adsorption is a surface-based process, while hydric deformation is initiated when water is being absorbed into the sample, i.e., when a specimen is immersed in the water. Absorption involves the whole volume of the material

Determining the purely hygroscopic strain can sometimes be difficult, especially in the direction parallel to reinforcing fibres in the case of composite materials [5, 6. In addition, hygric expansion is often not taken into account in practical measurements and calculations, although a higher content of moisture, particularly in the liquid state, can lead to hygric stresses in the same range as thermal stresses [7]. A higher coefficient of moisture expansion generally means higher stress and higher demand on the mechanical properties $[8$. The present study assesses the coefficient of moisture-induced expansion of plasters under both hygric and hydric loading. In addition, this study presents the long-term environmental effect on the water sorption capability of plasters.

\section{EXPERIMENTAL PROGRAM}

The hygric expansion was determined in the moisture range from dry material to $95 \%$ RH. Hygric wetting experiments were carried out in climatic chambers and the hydric expansion was monitored after samples were immersed in a water tank. Hygric loading was simulated by increasing the relative humidity in the chamber to $40 \%, 60 \%, 80 \%$ and $95 \%$. The relative humidity was kept constant at every humidity level for six weeks (Fig. 11). The temperature was kept constant at $21^{\circ} \mathrm{C}$ at all times.

The common principle of using a laser sensor for dilatation measurements was utilized for the monitoring of the hygric and subsequent hydric expansion (Fig. 2). The sensors measured distance without any contact with a front surface of the specimen. The specimen was placed in between two laser sensors on a special stainless-steel mount developed for the purpose of this study (Fig. 33. Measuring range of laser sensors was $5 \mathrm{~mm}$. Lasers worked with resolution $0.01 \%$ of full scale output. The measuring rate of the laser sensors was $1.5 \mathrm{kHz}$. The weight of the specimen was determined at the end of each loading sequence on a digital scale with $0.01 \mathrm{~g}$ accuracy.

A laser triangulation displacement sensor operated with a laser diode which projected a visible light spot onto the surface of the measurement target. "Triangulation" refers to the measuring of a distance by calculating an angle. The light reflected from the spot was imaged by an optical receiving system onto 


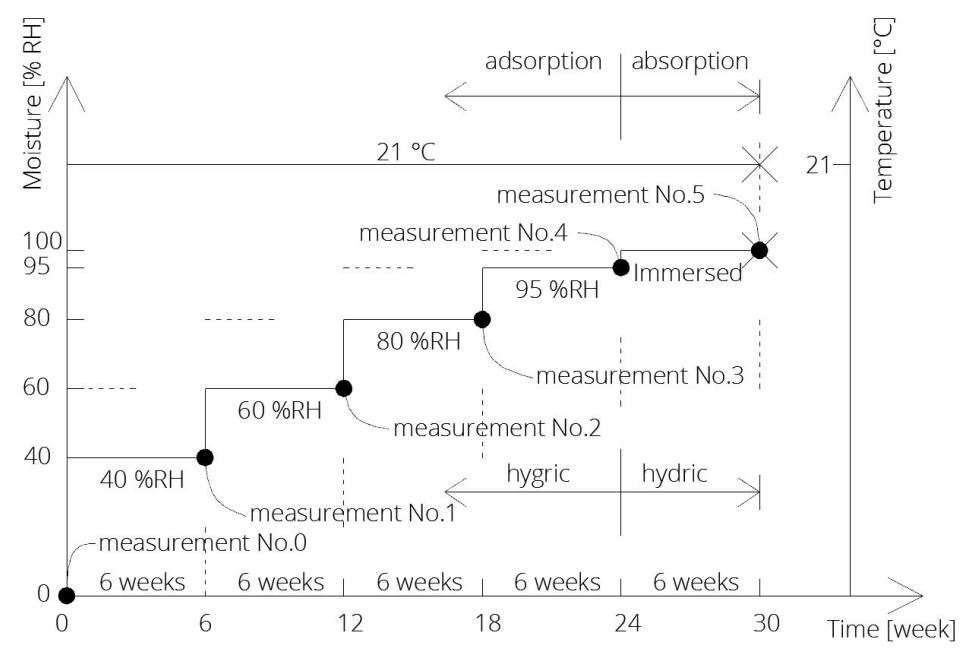

Figure 1. Climatic loading.

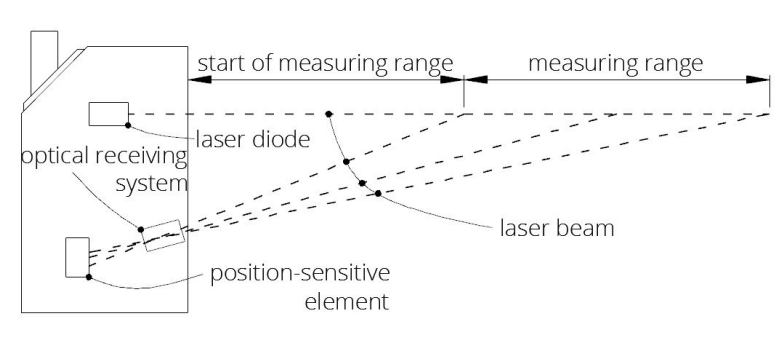

FiguRE 2. Principle of the laser sensor.

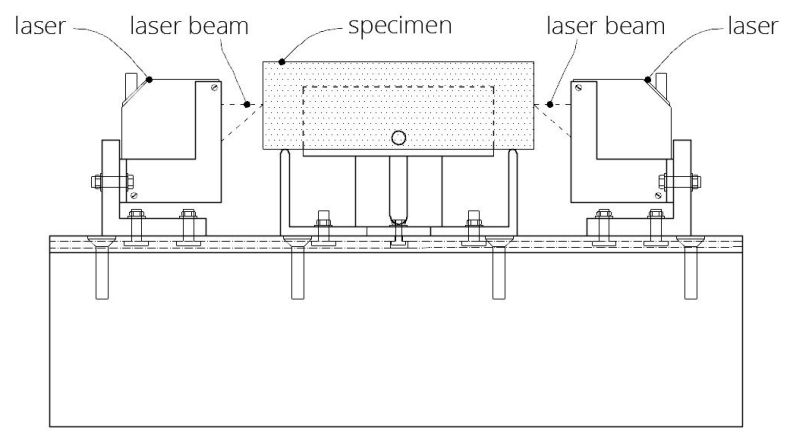

FiguRE 3. Measurement unit.

a position-sensitive element. If the light spot changed its position, this change was imaged on the receiving element and evaluated. The laser sensor used a semiconductor laser with a wavelength of $670 \mathrm{~nm}$. The maximum optical output power was $1 \mathrm{~mW}$. The sensor was classified as laser class II.

The laser beam was strongly bundled using a special lens design in order to detect only a few micrometres in diameter on the measured object. This was a particular benefit in the case of very small measured objects. Even when measurements on structured surfaces are required, a small spot size is often advantageous. The basic characteristics of the laser triangulation displacement sensor used in this study are shown in Tab. 1 .

\begin{tabular}{lc}
\hline Measuring range & $5 \mathrm{~mm}$ \\
Start/end of measuring range & $20 / 25 \mathrm{~mm}$ \\
Operation temperature & $0-50{ }^{\circ} \mathrm{C}$ \\
Operation relative humidity & $5-95 \%$ \\
Measuring rate & $1.5 \mathrm{kHz}$ \\
Resolution-static & $0.6 \mu \mathrm{m}$ \\
\hline
\end{tabular}

TABLE 1. Basic parameters of the laser sensor.

\section{MAterials}

The materials used in this study were specimens of commonly used plasters which are routinely in contact with outdoor environments. The moisture-induced strains were determined for the reference samples and also for the samples which were subjected to an outdoor environment for one year. The history of the temperature actions and the relative humidity actions on the one-year-old samples is shown in Figs. 4 and 5 respectively. The specimens of plasters used in this study were $160 \mathrm{~mm}$ in length; the side of the rectangular cross-section was $40 \mathrm{~mm}$.

The selected plasters used in this study are commercially available in the Czech Republic. The basic properties of these plasters are shown in Tab. 2 A detail characterisation of the plasters used in this study can be found in [9]. The consistency of the plasters was determined by a standard flow table test described by CSN EN 1015-3, and all plasters reached a consistency of $160 / 160 \mathrm{~mm}$. The coefficient of linear thermal expansion for plasters can usually be found in the range from $6.2 \times 10^{-6} \mathrm{~K}^{-1}$ to $15 \times 10^{-6} \mathrm{~K}^{-1}$ [ $]$.

\section{Results}

The sorption isotherms of the analysed plasters are presented in Fig. 6. The highest value of water sorption was achieved by the lightweight plaster P2 in both the reference and the one-year-old measurements. It is interesting to note that all water sorption isotherms, 


\begin{tabular}{lllll}
\hline Material & \multicolumn{1}{c}{ Commercial name } & \multicolumn{1}{c}{ Composition } & $w / c$ & $\varrho\left[\mathrm{kg} / \mathrm{m}^{3}\right]$ \\
\hline Plaster P1 & Baumit MPA 35 & Plaster with lime and cement & 0.22 & 1244 \\
\hline Plaster P2 & Baumit Thermo Putz & Lightweight plaster with perlite & 0.4 & 452 \\
\hline Plaster P3 & Baumit Sanova omítka W & Renovation plaster & 0.31 & 1183 \\
\hline Plaster P4 & Baumit Sanova pufferová omítka & Renovation plaster-brown coat & 0.34 & 1118 \\
\hline Plaster P5 & Baumit MVR Uni & Plaster suitable for & 0.24 & 1292 \\
& \multicolumn{2}{c}{ aerated-concrete walls } \\
\end{tabular}

TABle 2. Characterisation of commercial plasters used in this study 9 .

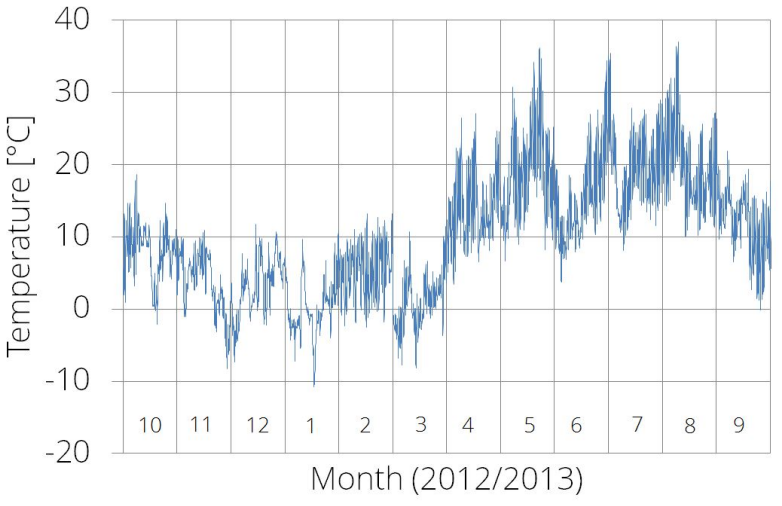

Figure 4. The temperature history.

\begin{tabular}{cccc}
\hline Sample & $a\left[10^{-6}\right]$ & $w_{0}\left[10^{-3}\right]$ & $R^{2}$ \\
\hline Plaster P1 & -37.0 & 23.5 & 0.999 \\
Plaster P2 & -72.5 & 20.0 & 0.999 \\
Plaster P3 & -36.5 & 19.6 & 0.999 \\
Plaster P4 & -47.2 & 29.7 & 0.997 \\
Plaster P5 & -28.9 & 22.4 & 0.996 \\
\hline
\end{tabular}

TABLE 3. Fitting parameters for reference samples.

gained after one year in outdoor environments, presented a reduced capacity for water sorption.

An approximation and smoothing of the measured moisture-induced strains for individual plasters (Fig. 7) was described, as follows, as a function of moisture content:

$$
\varepsilon(w)=\frac{a}{w+w_{0}}-\frac{a}{w_{0}},
$$

where $\varepsilon$ is the moisture-induced strain, $w$ is the moisture content by volume and $a$ and $w_{0}$ are fitting constants. This equation was chosen in order to fit the measured data with the best reliability, as presented in Tab. 3 and Tab. 4 .

The fitting parameters presented in Tab. 3 and Tab. 4 were determined by regression analysis using the least-squares method with an assumption that the data are independently and normally distributed with a common standard deviation.

The maximum moisture contents by volume for the individual samples and the maximum strain obtained

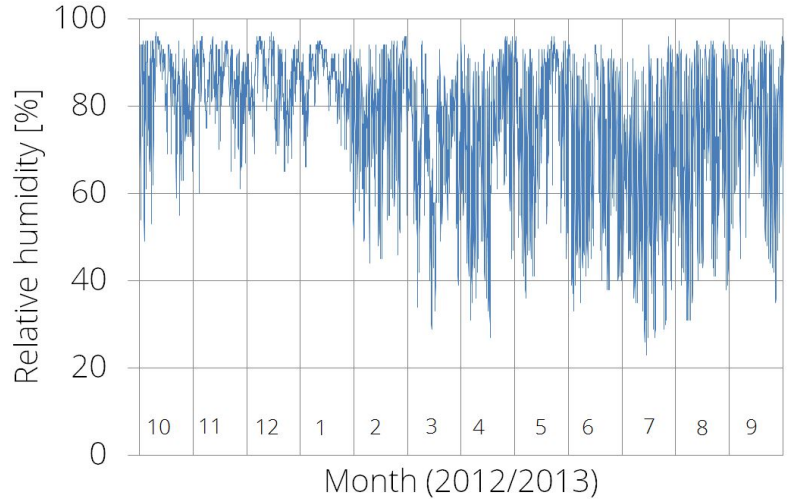

FiguRE 5. The relative humidity history.

\begin{tabular}{cccc}
\hline Sample & $a\left[10^{-6}\right]$ & $w_{0}\left[10^{-3}\right]$ & $R^{2}$ \\
\hline Plaster P1 & -4.61 & 8.79 & 0.999 \\
Plaster P2 & -21.7 & 10.9 & 0.997 \\
Plaster P3 & -8.96 & 10.1 & 0.994 \\
Plaster P4 & -18.2 & 18.1 & 0.996 \\
Plaster P5 & -11.2 & 15.3 & 0.991 \\
\hline
\end{tabular}

TABLE 4. Fitting parameters for one-year-old samples.

after the wetting experiments are listed in Tab. 5 The values are presented for the reference samples as well as for the samples which were subjected to the environmental loading for one year.

The data presented in Tab. 5 show the maximum moisture content and the related moisture-induced strain. Both parameters decreased when the plasters were subjected to an outdoor environment for one year prior to the testing. The value of the maximum moisture content for Plaster P1, Plaster P2, Plaster P3, Plaster P4 and Plaster P5 was reduced by $13.4 \%, 9.59 \%, 23.9 \%, 22.7 \%$ and $8.82 \%$ relative to the reference samples, respectively. The value of the maximum moisture-induced strain for Plaster P1, Plaster P2, Plaster P3, Plaster P4 and Plaster P5 was reduced by $65.6 \%, 41.5 \%, 55.7 \%, 35.0 \%$ and $40.6 \%$ relative to the reference samples, respectively.

The coefficient of moisture expansion $\alpha_{h}[-]$, including both hygric and hydric deformations, was determined as a derivation of the $\varepsilon(w)$ function, as presented in (1). The coefficient can therefore be 

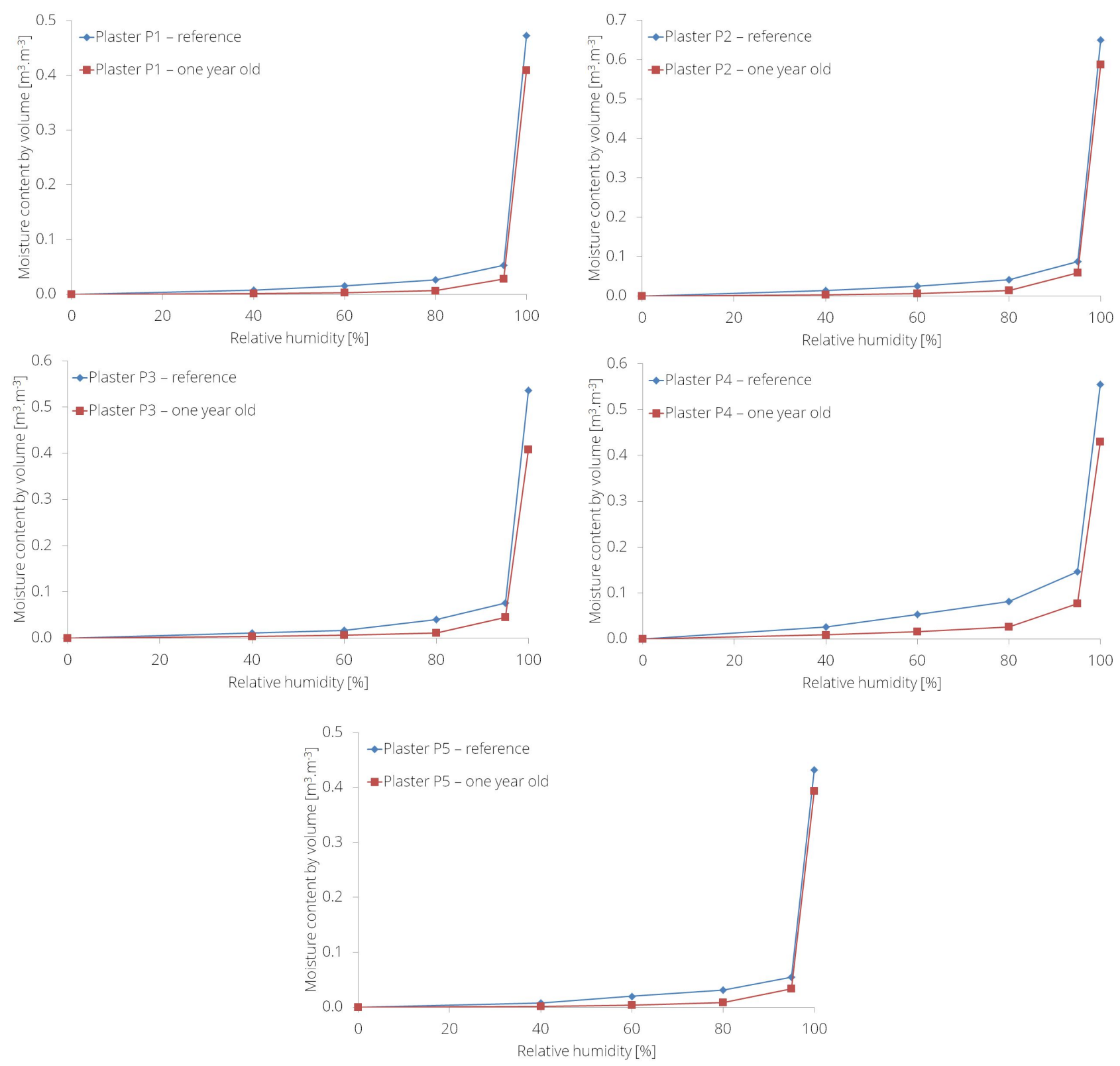

FiguRE 6. Sorption isotherms of studied plasters.

expressed as follows:

$$
\alpha_{h}=\frac{-a}{\left(w+w_{0}\right)^{2}}
$$

where $a, w$ and $w_{0}$ represent the same parameters as described in (1). The coefficient of moisture expansion for individual plasters is presented in Fig. 8

\section{Conclusions And Further OUTLOOK}

The coefficients of moisture-induced expansion, covering both hygric and hydric strains, were established in this study for different plasters. The moisture-induced strains demonstrated the significant influence of moisture content on deformation which might be induced in plasters due to moisture changes. These changes might be equal to or higher than the stresses caused

\begin{tabular}{lcl}
\hline \multicolumn{1}{c}{ Sample } & $\begin{array}{c}\text { Moisture } \\
{\left[\mathrm{m}^{3} \mathrm{~m}^{-3}\right]}\end{array}$ & $\begin{array}{l}\text { Strain } \\
{\left[10^{-3}\right]}\end{array}$ \\
\hline Plaster P1 - reference & 0.472 & 1.49 \\
Plaster P1 - one year old & 0.409 & 0.514 \\
\hline Plaster P2 - reference & 0.649 & 3.49 \\
Plaster P2 - one year old & 0.587 & 2.04 \\
\hline Plaster P3 - reference & 0.536 & 1.82 \\
Plaster P3 - one year old & 0.408 & 0.806 \\
\hline Plaster P4 - reference & 0.555 & 1.53 \\
Plaster P4 - one year old & 0.429 & 0.996 \\
\hline Plaster P5 - reference & 0.432 & 1.23 \\
Plaster P5 - one year old & 0.393 & 0.731 \\
\hline
\end{tabular}

TABLE 5. Maximum moisture content by volume and moisture-induced strain. 

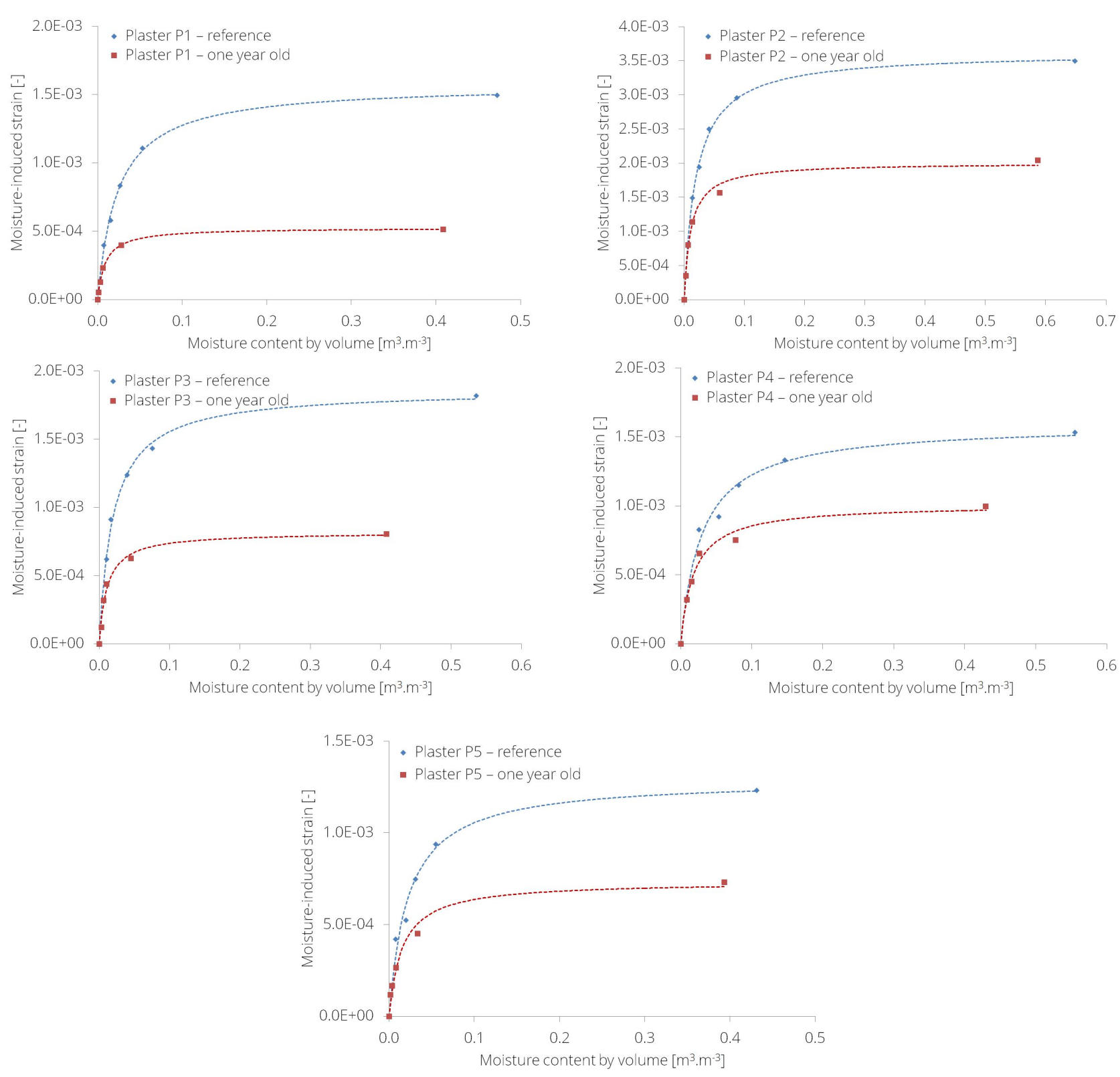

FIGURE 7. Strain development of studied plasters.

by temperature variations. In addition, it was verified experimentally that both strain and moisture content decreased when the samples were subjected to outdoor environments prior to the testing. The maximum moisture content of the one-year-old plasters which were subjected to environmental actions was reduced by $8 \%$ to $24 \%$ and the maximum strain was reduced by $35 \%$ to $66 \%$ relative to the reference samples.

The reference samples and the one-year-old samples were presented in this study. It is important to note that it is a fairly complex and highly time-consuming task to make proper measurements of moisture expansion. This is the main reason why no experimental work has been performed on the older samples so far. It is therefore highly desirable to extend the scope of our study presented here, and to verify the moistureinduced expansion on samples subjected to outdoor environments for more than a year.

\section{ACKNOWLEDGEMENTS}

The authors gratefully acknowledge the support provided by the Czech Science Foundation under project number GAP 105/12/G059. The authors would also like to acknowledge the assistance given by the technical staff of the Experimental Centre, Faculty of Civil Engineering, CTU in Prague, and by the students who participated in the project.

\section{REFERENCES}

[1] Baker, M. C.: Thermal and moisture deformations in building materials, Canadian Building Digest, 56, 1964, p. 1-4.

[2] T Ritchie, Moisture expansion of clay bricks and brickwork, National Research Council Canada, Division of Building Research 1975.

[3] T McNeilly, C Brick, Moisture expansion of clay bricks: An appraisal of past experience and current knowledge, Brick Development Research Institute 1985. 

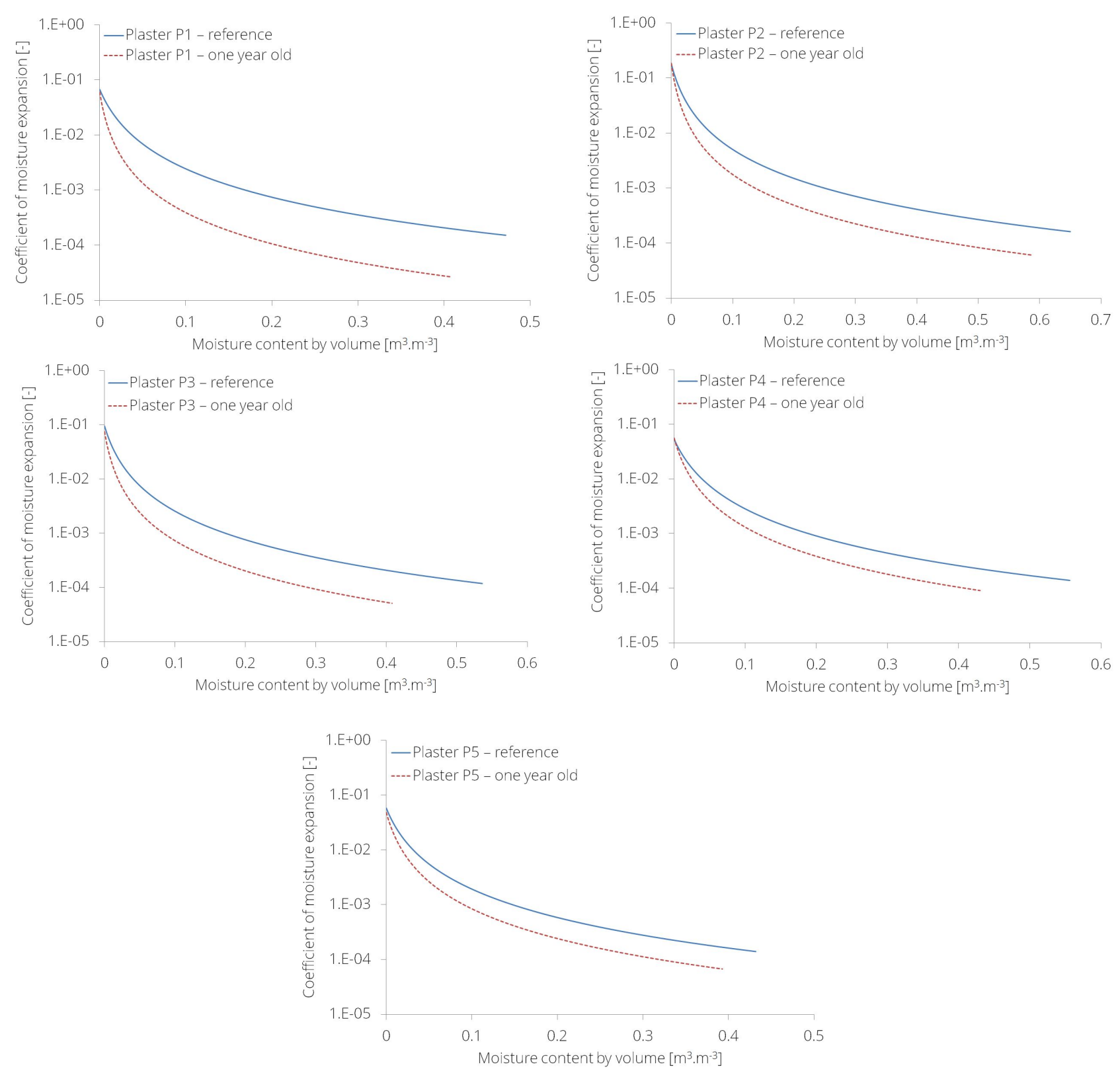

FIGURE 8. Coefficient of moisture expansion for studied plasters.

[4] S Siegesmund, H Dürrast, Physical and Mechanical Properties of Rocks, Stone in Architecture, Springer, 2014, pp. 97-224 DOI:10.1007/978-3-642-45155-3_3

[5] Ramezani-Dana, H., Casari, P., Perronnet, A., Fréour, S., Jacquemin, F., Lupi, C.: Hygroscopic strain measurement by fibre Bragg gratings sensors in organic matrix composites-Application to monitoring of a composite structure, Composites Part B: Engineering, 58, 2014, p. 76-82. DOI:10.1016/j.compositesb.2013.10.014

[6] Schulgasser, K.: Moisture and thermal expansion of wood, particle board and paper, International Paper Physics Conference, CPPA Tech. Section, 1987, p. 53-63.

[7] Toman, J., Černý, R.: Coupled thermal and moisture expansion of porous materials, Int. J. Thermophys., 17, 1996, p. 271-277. DOI:10.1007/BF01448229

[8] Černý, R., Kunca, A., Tydlitát, V., Drchalová, J., Rovnaníková, P.: Effect of pozzolanic admixtures on mechanical, thermal and hygric properties of lime plasters, Constr. Build. Mater., 20, 2006, p. 849-857. DOI:10.1016/j.conbuildmat.2005.07.002

[9] Čáchová, M., Koňáková, D., Vejmelková, E., Keppert, M., Polozhiy, K., Černý, R.: Heat and Water Vapor Transport Properties of Selected Commercially Produced Plasters, Advanced Materials Research, Trans Tech Publ, 2014, p. 90-93. www.scientific.net/AMR.982.90 [2015-06-01]. 